\title{
CATAPULTS INTO A DEADLY TRAP: THE UNIQUE PREY CAPTURE MECHANISM OF DROSERA GLANDULIGERA
}

Siegfried R. H. HartMeYer •Wittlinger Str. 5 • DE-79576 Weil am Rhein•Germany・s.hartmeyer@, t-online.de

IRMGaRd HaRTMEYER • Wittlinger Str. 5 • DE-79576 Weil am Rhein • Germany

Tom Masselter • Plant Biomechanics Group Freiburg • Botanic Garden • Faculty of Biology •

University of Freiburg • Schänzlestrasse $1 \cdot$ DE-79104 Freiburg im Breisgau $\bullet$ Germany

Robin Seidel - Plant Biomechanics Group Freiburg • Botanic Garden • Faculty of Biology •

University of Freiburg • Schänzlestrasse 1 • DE-79104 Freiburg im Breisgau • Germany

Thomas Speck • Plant Biomechanics Group Freiburg • Botanic Garden • Faculty of Biology •

University of Freiburg • Schänzlestrasse $1 \cdot$ DE-79104 Freiburg im Breisgau $\bullet$ Germany

Simon Poppinga • Plant Biomechanics Group Freiburg • Botanic Garden • Faculty of Biology •

University of Freiburg • Schänzlestrasse $1 \cdot$ DE-79104 Freiburg im Breisgau • Germany

Keywords: catapult-flypaper-trap, cultivation, Drosera glanduligera, functional morphology, plant biomechanics, snap-tentacles.

\section{Introduction}

Active trapping mechanisms constitute some of the most spectacular examples for how carnivorous plants catch their prey (Darwin 1875; Lloyd 1942; Juniper et al. 1989). Recently, we showed that the Pimpernel Sundew (Drosera glanduligera Lehm.) possesses active combined catapult-flypapertraps which work with a sophisticated two-step mechanism (Poppinga et al. 2012): after mechanical stimulation, elongated marginal snap-tentacles at the trap periphery rapidly fling the prey, often with its dorsal side first, onto sticky glue-tentacles on the leaf blade within less than 1/10 second. Subsequently, stimulated mechanically by the impact, slower glue-tentacles lift the prey into a deeply concave leaf-center where digestion takes place. The snap-tentacles have been analyzed in respect to their kinematics, functional morphology and anatomy, and our observations confirm a complex adaptation to carnivory. From the very beginning we intended to accompany our research with informative documentaries (Hartmeyer \& Hartmeyer 2012a,b) and to provide this additional article to the readers of the CPN. It features a brief summary of the main results, some extended background information, further original morphological observations, and interpretations (surely featuring issues to discuss) as well as a detailed description of how to cultivate this sophisticated carnivorous plant.

\section{Background Story}

Remarkably, the rapid snap-tentacle motion of the Pimpernel Sundew has not been noticed for a long time, ranging for more than 150 years from the species description (Lehmann 1844) until the end of the last millennium. Even in the otherwise comprehensive benchmark books on Australian carnivorous plants published more than one hundred years after the first species description, this mechanism was not mentioned (Erickson 1968; Lowrie 1989). The same holds for the article of Seine \& Barthlott (1993) who provided a detailed comparative anatomical survey of the apical tentacle parts of numerous Drosera species and described $D$. glanduligera to possess bilaterally symmetric tentacles with a raised head, a feature that is unique in the genus. The first person to report on snap-tentacle action 
was Richard Davion who published two important field reports in "Flytrap News", the newsletter of the Carnivorous Plant Society of New South Wales (Davion 1995; 1999), mentioning that “... the dry pads [of the Pimpernel Sundew] are quite able to flick ants into the center of the traps." He noticed the fast snap-tentacle motion of D. glanduligera already in 1974 at Cannington Swamp near Perth as a 9 -year-old boy (pers. comm.). In 2003, Davion contacted Irmgard and Siegfried Hartmeyer and provided seeds with the request to examine and confirm the rapid motion, which was successfully accomplished and published in Das Taublatt, the journal of the German CPS (GFP) (Hartmeyer \& Hartmeyer 2005). In addition, a video documentary (Hartmeyer \& Hartmeyer 2006) with detailed macro-shots was released and presented at the 2008 ICPS conference in Frostburg, constituting a comparative morphology of the multifold elongated marginal tentacles in the genus Drosera and also including first speed measurements (see also a contribution in McPherson 2008). An upgraded article in the CPN on the snap-tentacle phenomenon followed in 2010 (Hartmeyer \& Hartmeyer 2010). The fast tentacle motion performed by a Drosera species drew the attention of plant biologists who work on "rapid plants" on the otherwise rather inconspicuous Pimpernel Sundew. However, Davion's assertion that prey can be thrown into the leaf-center became meanwhile adopted by several authors (Gibson \& Waller 2009; Bourke \& Nunn 2012), but was never confirmed by prey capture experiments or scientifically conducted observations in the field. In January 2012 we decided to bridge this knowledge gap by experimentally feeding cultivated $D$. glanduligera plants to record the trapping motion and furthermore to conduct morphological and anatomical investigations.

\section{Cultivation of Drosera glanduligera}

The Pimpernel Sundew is an annual winter grower with a wide distribution range across the southern regions of Australia (Erickson 1968). Therefore it needs cool nights but warm and bright days to thrive well. After cultivating the plants for almost ten years in the Northern Hemisphere, our observations show that the germination of $D$. glanduligera seeds is triggered when the night temperature drops significantly below $8^{\circ}-10^{\circ} \mathrm{C}$ for approximately 3-7 days after the seeds have been sown on a standard peat-sand-mixture (partly containing also pumice gravel or Perlite) in June, and remain on the wet soil in full sunlight during the summer. A reduced "hot season" may avoid germination in time and cause a delay for a whole year (see below). Due to decreasing night temperatures in autumn, germination usually starts in October in the south-western region of Germany. In 2012, the first seeds sown in early June germinated after only three cool nights $\left(4^{\circ}-5^{\circ} \mathrm{C}\right)$ in late September. We do not use any additional treatments to improve the germination such as smoked water, gibberellic acid, or other methods and substances, respectively. For the experiments described, approximately 300 seeds were sown in midJuly 2010, from which about 200 germinated with a surprising extreme delay in October 2011, and from which approximately 150 plants matured.

In order to thrive well, the temperature after germination has to remain only slightly above $0^{\circ} \mathrm{C}$ at night until the beginning of March. During the daytime, plenty of light and temperatures of up to $15^{\circ}-25^{\circ} \mathrm{C}$ are necessary. In January 2012 , the temperature for our test plants ranged between $0.8^{\circ}$ and $27^{\circ} \mathrm{C}$. An electric frost protection unit avoided a cooling down below the freezing point, and during the day we achieved ideal conditions with a sunny south-western exposure position, combined with a 400 watt metal halide lamp. If the night temperature rises above $8^{\circ} \mathrm{C}$ before March, premature flowering is triggered, resulting in early plant death and a reduced seed production.

Apart from this, another factor proved to be extremely important for the plants: in addition to the correct light and temperature conditions the plants need constant nutrition supply from the very beginning. Only then the seedlings metamorphose, in the first 4-6 weeks of initial growth, from the juvenile 
phase with simple sticky traps to the adult phase with catapult-trap leaves. Collembola (springtails) most likely constitute the main natural prey for D. glanduligera and other Australian sundew species (Verbeek \& Boasson 1993; Watson et al. 1982). Ideally, if one has living springtails in the plant pots and soil they will be successfully caught and digested (Hartmeyer \& Hartmeyer 2010). Otherwise, the feeding necessary for $D$. glanduligera is quite time-consuming and takes place in several consecutive phases, depending on the age and size of the plants. We use standard fish food flakes which are comminuted between the fingers. The smallest pieces are picked up using a forceps (best with magnifier glass) to feed the plants leaf by leaf. This procedure is performed for plants of about $2-5 \mathrm{~mm}$ in diameter. In the next phase, when the leaves are about $3 \mathrm{~mm}$ in diameter, we feed them with fruit-flies that are commercially available in garden centers or pet shops. The flies are cut into appropriate pieces (considering the small leaves) using a scalpel. This provides ideal nutrition to the plants as early as possible, avoids over-feeding them, and reduces the risk of mold formation. Later, when the leaves are about 5-6 $\mathrm{mm}$ in diameter, there is no major risk in feeding even 2-3 fruit-flies at a time per leaf. New leaves are reproduced every 3-4 days until the end of the growing season. Therefore, the feeding should be repeated about twice per week to achieve permanent growth.

\section{Flowering, Seed Production, and Seed Morphology}

With the above mentioned conditions, flowering was observed to take place from early March until late April 2012 (Fig. 1a). When the flowers are open, night temperature may rise to $10^{\circ}-12^{\circ} \mathrm{C}$ and the day temperature may exceed even $30^{\circ} \mathrm{C}$ without any visible deterioration of the plants. Providing as much light as possible is highly recommended.

In cultivation the plants are mostly self-pollinating and multiple seed-pods will emerge on the inflorescence stalk, while new flowers are still produced on the stalk apex (Fig. 1b). In May 2012 we observed most of the seed-pods to ripen. At the same time, the rosettes started to become brownish and the plants died back within a few days. By end of May to early June 2012 we harvested the seeds.
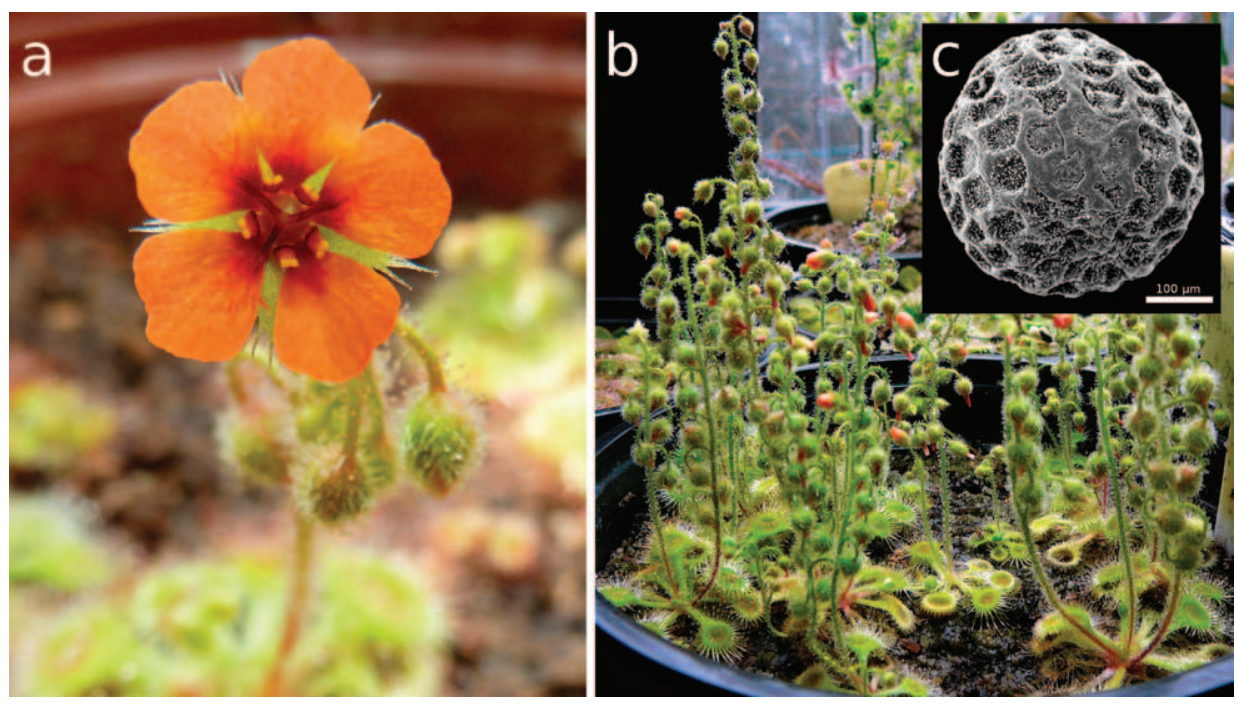

Figure 1: Drosera glanduligera in cultivation. a) Flower. b) Adult plants producing numerous seed capsules on the inflorescence stalks. c) Scanning electron microscopy image of a seed grain featuring concave testa cells and epicuticular wax crystalloids. 
However, it is actually quite tedious to free them from dried plant matter, sticking to the still gluey seed pods. Each plant can produce several hundred seeds. Transport by wind or ejection caused by rain are, in our opinion, the most probable means by which the Pimpernel Sundew seeds are being dispersed, but studies from the field are missing so far. The spherical seeds are approximately $400 \mu \mathrm{m}$ in diameter and are characterized by a surface with concave testa cells (Fig. 1c). As concave cells are very rarely found in fresh plant material but regularly on dry seed surfaces (Barthlott \& Hunt 2000; Koch et al. 2008), the inward deflection of the outer epidermis wall is most probably caused by water loss and shrinkage. Moreover, epicuticular wax crystalloids of the granule and rodlet types, typified according to Barthlott et al. (1998), are uniformly distributed on the testa.

\section{Prey Capture Experiments}

For our prey capture experiments we used common fruit-flies (Drosophila melanogaster). Due to their commercial availability and easy care they were perfect specimens for our tests, although they are unlikely to be the natural prey. The intention was to test if snap-tentacles can fling prey animals (Davion 1995, 1999), i.e. to elucidate their role in prey capture, under laboratory experimental conditions. It is still up to future studies to record snap-tentacle behavior in the plant's habitat with natural prey (springtails, ants) and to identify its importance for the plant. For a detailed description of "Materials and Methods" and an outlook for future studies we refer to our original article (Poppinga et al. 2012).

We placed flies next to the plants and recorded trapping action with a HDV camcorder and a highspeed camera with a recording speed of 2000 fps. The videos obtained (Hartmeyer \& Hartmeyer 2012a,b; Poppinga et al. 2012) clearly show that the rapid catapult function of snap-tentacles is combined with a slower "band-conveyor" mechanism carried out by the more centrally arranged sticky gluetentacles. First, the prey is lifted and thrown onto the trap leaf by snap-tentacles which, after mechanical stimulation by the animal, rapidly bend towards the leaf center within 75 milliseconds. The prey now is in a very disadvantageous position, because in most captures observed it was attached with its dorsal side first to the glue-tentacles, and we hypothesize that this mechanism also accounts for effectively immobilizing the prey. Owing to the mechanical impact, glue-tentacles also start to bend towards the trap center, but much slower, lasting approximately two minutes (which still is quite a fast Drosera tentacle movement). Hereby prey is drawn into the deeply concave leaf-center where digestion takes place, probably well-protected from kleptoparasites as reported from Drosera erythrorhiza (Watson et al. 1982). Unlike in many other sundews (Darwin 1875; Lloyd 1942; Williams 1976; Juniper et al. 1989), we did not observe leaf blade movement after capture of prey. Such a sophisticated, combined two-step trapping mechanism is unique in the plant kingdom, and we propose to use the term "active catapultflypaper-trap" exclusively for Drosera glanduligera. A passive catapult-pitfall-trap system, enabled by a semi-slippery trap surface and initiated by the impact force of raindrops, has recently been described for the Nepenthes gracilis pitcher plant (Bauer et al. 2012), constituting a further example of a "hybrid trapping strategy" (Rice 2007).

\section{Tentacle Motion Analysis}

How can snap-tentacles move so fast? Active plant movements (e.g., the leaflet folding of the famous sensitive Mimosa pudica) are often enabled by changes in turgor pressure (cell sap pressure) in antagonistically acting cellular tissues called pulvini (Braam 2005). Such systems are based on a displacement of water through a porous medium, the pulvinus tissue, and hence are actuated hydraulically. The duration of the fluid flow, and therefore the duration of the whole movement, depends on the 
thickness of the tissue the fluid has to pass. To move fast, the moving organ hence has to be small (as the hydraulically actuated Mimosa pulvinus (Volkov et al. 2010)), or must rely on a simple but effective "trick": like in a bow, stored elastic energy can be used to generate extremely fast motions "on demand" (Skotheim \& Mahadevan 2005; Dumais \& Forterre 2012). For example, the Venus Flytrap features large and fast traps (snapping lasts $\sim 100 \mathrm{~ms}$ ) and hence uses a buckling instability to perform their action, comparable with a rubber-popper-toy (Forterre et al. 2005). Other examples are bladderworts. Although their trapdoors are quite small, their movement is also too rapid to be actuated purely hydraulically when performing their "ultra-fast" opening motion in less than a millisecond (Vincent et al. 2011). The fastest movements known in plants are achieved by explosive fracture and are not reversible, e.g., the bursting fruits of the Sandbox Tree (Hura crepitans) (Swaine \& Beer 1977).

Having seen the snap-tentacle bending motion fully time resolved for the first time we also first believed that an elastic instability is involved. More precisely, as it is a long filiform structure that changes its curvature in short time ( $75 \mathrm{~ms}$ ) we assumed a similar mechanism as present in certain bicycle reflector bands that one strikes against the wrist to make it curl. Here, a long, flat and relatively stiff band with an initial transverse concave curvature of the reflector surface abruptly switches this curvature to convex (snap-buckling) after mechanical disturbance, which entails the fast rolling-in of the whole band (that has the intrinsic mechanical property to curl). Surprisingly, we found that the transverse axis of the tentacle does not undergo a sudden geometrical change, and that there are no noticeable anatomical features (e.g., thickened cell walls) that could take part in storing elastic energy (see also "Tentacle Morphology and Anatomy"). As described in our original study, it can be calculated that snap-tentacles theoretically are small enough to be actuated completely hydraulically. Hence, we interpret the fast motion to be due to a change in turgor pressure in antagonizing tissue layers, but further experiments, especially in physiology, are needed for verification. As outlined in detail in the original article (Poppinga et al. 2012), snap-tentacles function only once which is presumably due to collapsing epidermal cells.

\section{Tentacle Morphology and Anatomy}

The spoon-shaped trap leaves of $D$. glanduligera each carry a multitude of glue-tentacles, and in adult plants about 12-18 catapulting snap-tentacles that extend horizontally (in the plane of the lamina). Mechanical stimuli on the heads of both tentacle types entail bending motions, as described in the above section. The sticky tentacles show a bauplan (body plan) typical for Drosera tentacles by consisting of a cylindrical stalk, emerging almost vertically from the leaf lamina, and a more or less spherical, mucussecreting head. The region of stalk-head-connection, where the stalk is thinnest, is generally considered as the mechanoreceptor region (Williams 1976). Although we recorded the glue-tentacle motion, we did not investigate their anatomy in detail.

Excised snap-tentacles were analyzed with a light microscope and a scanning electron microscope. Five $\mu \mathrm{m}$ semi-thin transverse and longitudinal sections with toluidine blue staining were analyzed with the light microscope. For full details of materials and methods we refer to our original article (Poppinga et al. 2012). As detailed by Seine \& Barthlott (1993), the snap-tentacles are bilaterally symmetric. The stalk is flattened with a so-called terminal disc, somewhat resembling a human hand, that carries the mucus-free head (Fig. 2 and Front Cover). The flattened stalk most presumably accounts for the uniplanar, circular bending movement the snap-tentacles perform towards the trap leaf, whereas cylindrical glue tentacles can bend in more than one plane. The snap-tentacle's head-stalk-connection is very thin and most likely plays an important role in perception of mechanical stimuli (Fig. 2). Laterally on the stalk, small sessile glands of unknown function are visible (Fig. 3a,b). The snap-tentacle stalk consists of outer epidermal cells, parenchymatous inner cells (Fig. 3c) and vascular tissue. The latter consists of 

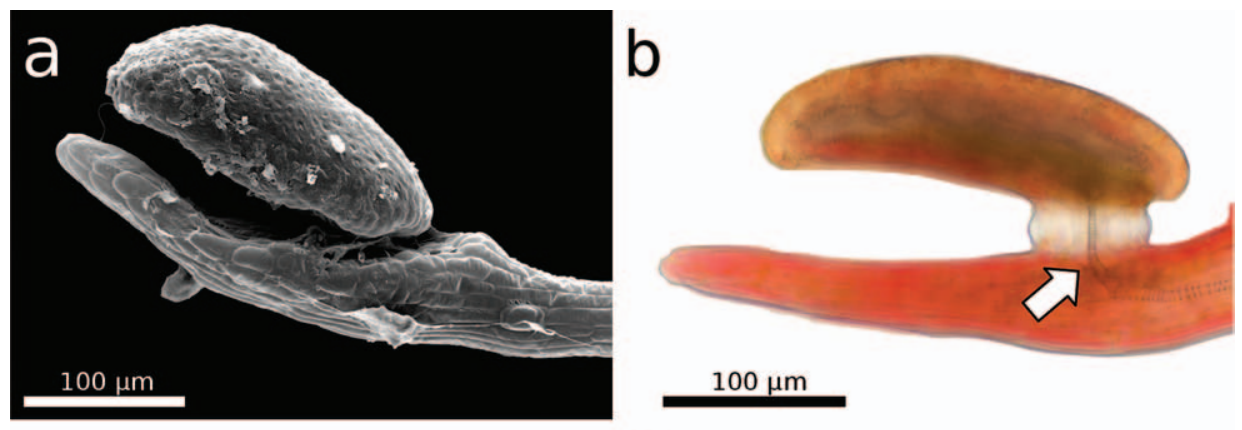

$100 \mu \mathrm{m}$
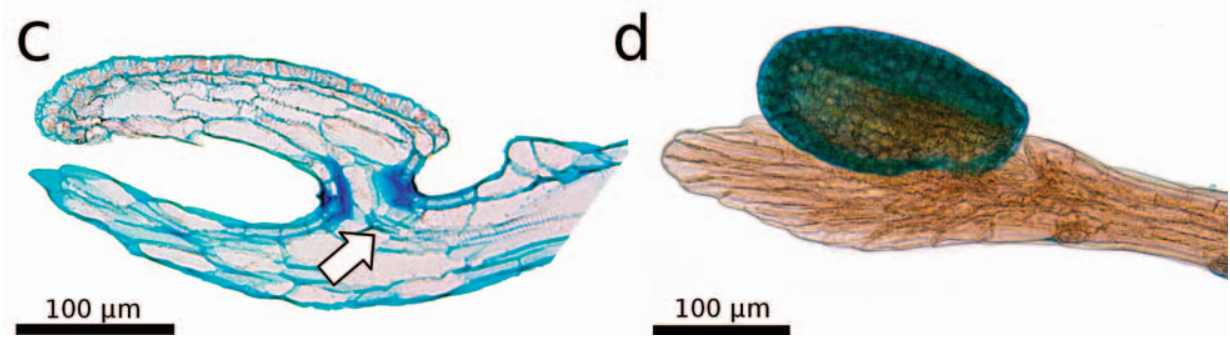

$100 \mu \mathrm{m}$

Figure 2: The snap-tentacle head is raised above the stalk's terminal disc, which somewhat resembles a human hand. a) Scanning electron microscopy image. b,c,d) Light microscopy images. b,c) The conducting strand is well visible (arrows). c) $5 \mu \mathrm{m}$ semi-thin longitudinal section, stained with toluidine blue. The thin stalk-head-connection most presumably plays an important role in reception of mechanical stimuli. d) The tentacle head is stained with toluidine blue.

a tracheid system (Fig. 4a), including a branched xylem in the head (see also Williams \& Pickard 1974; Williams 1976) that is connected to a single conducting strand in the center of the stalk (Fig. 2b,c). Epidermal and parenchymatous cells are elongated, of variable diameters, and do not feature significantly thickened cell walls, as already described in the section "Tentacle Motion Analysis" (Fig. 3c).

As far as we could observe, the conducting strand in the stalk is disconnected from the leaf lamina by ending close to the hinge-zone (Fig. 4a). The hinge zone is situated near the tentacle base and depicts the zone where snap-tentacles bend during the fast motion (Hartmeyer \& Hartmeyer 2010; Poppinga et al. 2012). Interestingly, here also exists a constriction with a layer of cells that appear to be somewhat pre-cut and thereby constitute a "fault zone" (Fig. 4b). When a slight lateral mechanical force is applied to a snap-tentacle, it will break at this region (Fig. 4b). Although the snap-tentacle bending is extremely fast and most presumably generates comparably high compressive and tension forces on the cellular tissues, there exists, hence, also a mechanical weak point (or predetermined breaking point) in this region. It can be speculated that the conducting strand adds mechanical stiffness to the apical snap-tentacle part, which was observed to remain straight during the motion. On the other hand, such a strand would impede the fast bending motion of the hinge-zone. A detailed investigation of the isolated tracheid system and of the "breaking point" is a matter for future studies.

\section{Transitional Stages of Tentacle Morphology during Ontogeny}

Morphological characteristics of trap leaves and their tentacles in different ontogenetic stages ranging from seedlings to adult plants were observed with a ProScope HR USB-microscope (Bodelin Tech- 


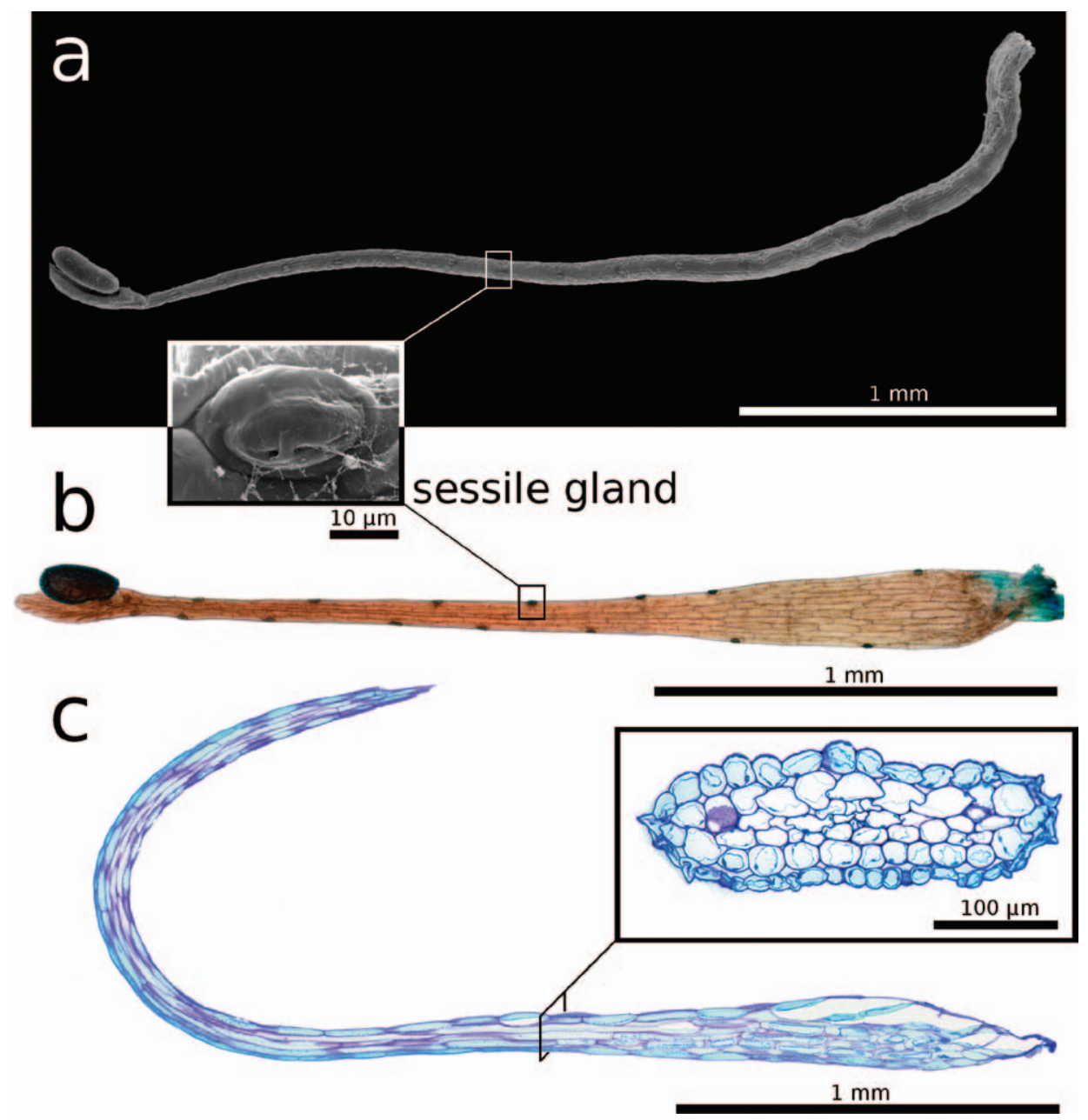

Figure 3: Snap-tentacle morphology and anatomy. a) Scanning electron microscopy image. b) Light microscopy image. a, b) Sessile glands on the stalk. c) 5 um semi-thin longitudinal section, the insert shows a transverse section, of the snap-tentacle stalk, both stained with toluidine blue.

nologies, Oregon, USA), using a 200-fold magnification lens. "Modern" sundew species that feature snap-tentacles typically produce two cotyledons which are only exceptionally carnivorous, as in $D$. ultramafica where they possess a few sticky tentacles (pers. observ.). Additionally to the typical gluetentacles on the lamina, all first trap leaves of these species possess three to five elongated, mucus-free and bilaterally symmetrical snap-tentacles that extend in the plane of the lamina. Hence, all these seedlings possess fully developed snap-tentacles from the very beginning, which are able to bend (most presumably by turgor-movement) in a time range between approximately five seconds to a few minutes, depending on the species and the surrounding temperature. The appearance of different snap-tentacles in the genus Drosera has been examined during the last decade in more than 100 different species (Hartmeyer \& Hartmeyer 2010). 


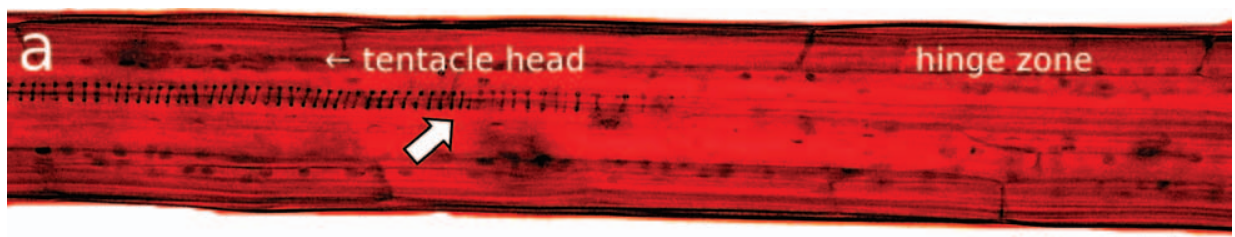

$100 \mu \mathrm{m}$
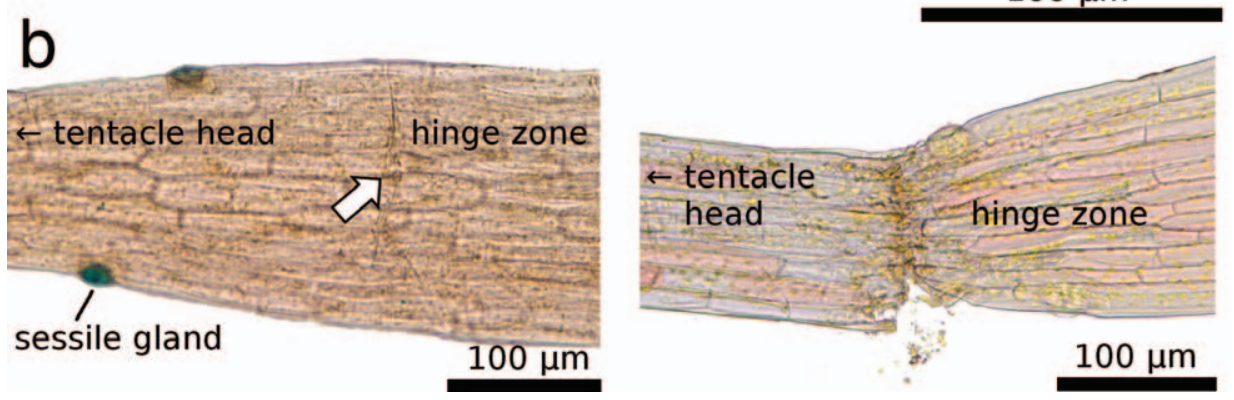

Figure 4: Light microscopy images of the transition zone close to the hinge region, which is characterized by a) a disconnected conducting strand (arrow, for better visibility structures here were enhanced by adjustment of brightness and contrast), and b) by a predetermined breaking region with a layer of cells that appear as a pre-cut "fault zone" (arrow) that leads to tentacle rupture when a lateral force is applied.

Drosera glanduligera seeds germinate without developing visible cotyledons; the first leaf already is a fully functional sticky trap growing in an upright direction from the seed, but without any snap-tentacles. The following three to four leaf generations show intermediate developmental stages during which the elongated marginal tentacles significantly change their morphology. The more or less spherical (symmetric), mucus-producing head becomes replaced by the glue-free, bilaterally symmetric, raised head as described above. As the hinge-zone of the stalk becomes more and more pronounced, the continuous conducting strand (Fig. 5) becomes disconnected from the lamina during the transitional stages just at the hinge region (Fig. 4). Also, the cavity for digestion in the center of the leaf becomes more and more distinctive. In cultivation, the first fully functional combined catapult-flypaper-traps emerge about six weeks after germination. Although the first catapulting tentacles still look very tender, they are nevertheless already capable of flinging springtails effectively onto the leaf-center (pers. observ.).

\section{Discussion}

A raised tentacle head, a disconnected conducting strand and a preformed tentacle "breaking region", a unique hinge-zone, and a rapid motion comparable with the trapping speeds of Aldrovanda and Dionaea (Ashida 1934; Forterre et al. 2005; Poppinga \& Joyeux 2011) distinguish the catapulting snap-tentacles of $D$. glanduligera clearly from all other (much slower) snap-tentacles found in other sundew species, such as D. burmannii (Hartmeyer \& Hartmeyer 2010) or D. rotundifolia (Darwin 1875). The combined catapult-flypaper-trap comprises a combination of 12-18 one-shot devices (the marginal catapults) with a subsequent "band-conveyor" consisting of sticky tentacles. Glue-tentacles are both able to draw larger prey into the center, and to return to their initial position after the delivery of the prey in order to wait for the next victim becoming catapulted by snap-tentacles. We hypothesize that catapulting snap-tentacles enable successful capture (and retention) of comparably large prey animals that otherwise could escape from glue-only traps. 


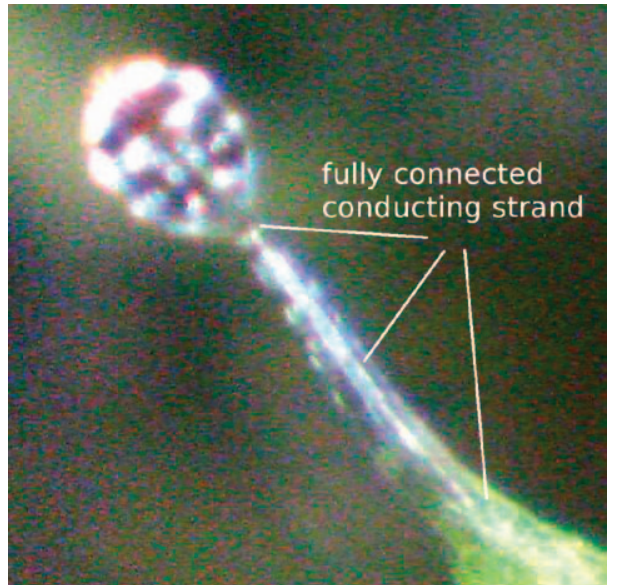

Figure 5: Digitally enlarged USB-microscope image of a glue-tentacle in an early stage of D. glanduligera development, which possess an obviously fully functional conducting strand. They later become replaced by catapult-snap-tentacles in which the strand is disconnected (see Fig. 4).
We hypothesize that the capture of larger prey animals occurs only occasionally and that the capture of smaller animals, such as springtails, being probably the main prey animals (see also "Cultivation of Drosera glanduligera"), occurs much more frequently. Collembola are almost ubiquitous and find ideal life conditions in leaf litter (Fjellberg 1998), which most probably is also true for the prey species Hypogastrura vernalis identified by Watson et al. (1982). Additionally, Collembola are reported to be caught in high numbers by other co-occurring Australian Drosera species (Watson et al. 1982; Verbeek \& Boasson 1993). These micro-arthropods might well be attracted by chemical volatiles that come along with wilting and wilted leaves, and we hypothesize that this might be the case not only for $D$. glanduligera, but also for many other carnivorous plants. Especially in perennial species growing as ground rosettes, the accumulation of dead plant material could facilitate an effective attraction. The Pimpernel Sundew has perfected its traps by the outstretched

catapulting tentacles. Another speculation is raised by the question about the function of the sessile glands on the snap-tentacle stalks (Fig. 3a,b; 4b). Perhaps these glands also take an active part in prey attraction by emitting scents. Recently, attraction by sex-specific volatiles was reported for moss where the allured micro-arthropods act as sperm dispersers (Rosenstiel et al. 2012). This finding highlights how Collembola and other arthropod groups might be chemically attracted. Perhaps, such mechanisms have evolved independently more frequently and for more different purposes in plants than thought before.

\section{References}

Ashida, J. 1934. Studies on the leaf movement of Aldrovanda vesiculosa L. I. Process and mechanism of the movement. Mem. Coll. Sci. Kyoto Imp. Univ. Ser. B 9: 141-244.

Barthlott, W., Neinhuis, C., Cutler, D., Ditsch, F., Meusel, I., Theisen, I., and Wilhelmi, H. 1998. Classification and terminology of plant epicuticular waxes. Bot. J. Linn. Soc. 126: 237-260.

Barthlott, W., and Hunt, D. 2000. Seed-diversity in Cactaceae subfam. Cactoideae. In: Succulent Plant Research Vol. 5, ed. D. Hundt. David Hunt: Milborne Port.

Bauer, U., Di Giusto, B., Skepper, J., Grafe, T.U., and Federle, W. 2012. With a flick of the lid: a novel trapping mechanism in Nepenthes gracilis pitcher plants. PLoS ONE 7(6): e38951.

Bourke, G., and Nunn, R. 2012. Australian Carnivorous Plants. Redfern Natural History Productions, Poole, Dorset.

Braam, J. 2005. In touch: plant responses to mechanical stimuli. New Phytol. 165: 373-389.

Darwin, C. 1875. Insectivorous Plants. John Murray, London.

Davion, R. 1995. Now you see it - Now you don’t. Flytrap News 8: 17.

Davion, R. 1999. That damned elusive Pimpernel. Flytrap News 13: 10.

Dumais, J., and Forterre, Y. 2012. "Vegetable dynamicks": the role of water in plant movements. Annu.

Rev. Fluid Mech. 44: 453-478. 
Erickson, R. 1968. Plants of Prey. Lamb Paterson, Perth.

Fjellberg, A. 1998. The Collembola of Fennoscandia and Denmark Part 1: Poduromorpha. Brill, Leiden.

Forterre, Y., Skotheim, J.M., Dumais, J., and Mahadevan, L. 2005. How the Venus Flytrap snaps. Nature 433: 421-425.

Gibson, T.C., and Waller, D.M. 2009. Evolving Darwin's 'most wonderful' plant: ecological steps to a snap-trap. New Phytol. 183: 575-587.

Hartmeyer, I., and Hartmeyer, S.R.H. 2005. Drosera glanduligera - Der Sonnentau mit "Klapp-Tentakeln". Das Taublatt 2005/2: 34-38.

Hartmeyer, I., and Hartmeyer, S.R.H. 2006. Drosera: Snap-Tentacles and Runway Lights. DVD documentary, Hunting Veggies, Weil am Rhein. Also http:/www.youtube.com/watch?v=BY7z15f3Vwg uploaded by ICPStv on Apr 16, 2010.

Hartmeyer, I., and Hartmeyer, S.R.H. 2010. Snap-tentacles and runway lights. Carniv. Pl. Newslett. 39: 101-113.

Hartmeyer, I., and Hartmeyer, S.R.H. 2012a. The Catapult-Flypaper-Trap / Die Katapult-Leimfalle (Video: Das Katapult der Diva). DVD documentary, Hunting Veggies, Weil am Rhein. Also http:// www.youtube.com/watch?v=Zzi3XDQs-i0 uploaded Sep. 26, 2012 by S.R.H. Hartmeyer.

Hartmeyer, I., and Hartmeyer, S.R.H. 2012b. Catapult-Flypaper-Trap: Prey-Catching Digest / Katapult-Leimfalle: Beutefang Kurzfilm . Hunting Veggies, Weil am Rhein. http:/www.youtube.com/ watch? $\mathrm{v}=\mathrm{eFShLcxNswk}$ published Nov. 13, 2012 by S.R.H. Hartmeyer.

Juniper, B.E., Robins, R.J., and Joel, D.M. 1989. The Carnivorous Plants. Academic Press, London.

Koch, K., Bhushan, B., and Barthlott, W. 2008. Diversity of structure, morphology and wetting of plant surfaces. Soft Matter 4: 1943-1963.

Lehmann, J.G.C. 1844. Nov. Stirp. Pug. 8: 37.

Lloyd, F.E. 1942. The Carnivorous Plants. Chronica Botanica, Waltham.

Lowrie, A. 1989. Carnivorous Plants of Australia Vol. 2. University of Western Australia Press, Perth.

McPherson, S. 2008. Glistening Carnivores - The Sticky-leaved Insect-Eating Plants. Redfern Natural History Productions, Poole, Dorset.

Poppinga, S., and Joyeux, M. 2011. Different mechanics of snap-trapping in the two closely related carnivorous plants Dionaea muscipula and Aldrovanda vesiculosa. Phys. Rev. E 84: 041928.

Poppinga, S., Hartmeyer, S.R.H., Seidel, R., Masselter, T., Hartmeyer, I., and Speck, T. 2012. Catapulting tentacles in a sticky carnivorous plant. PLoS ONE 7(9): e45735.

Rosenstiel, T.N., Shortlidge, E.E., Melnychenko, A.N., Pankow, J.F., and Eppley, S. 2012. Sex-specific volatile compounds influence microarthropod-mediated fertilization of moss. Nature 489: 431-433.

Rice, B. 2007. Carnivorous plants with hybrid trapping strategies. Carniv. Pl. Newslett. 36: 23-27.

Seine, R., and Barthlott, W. 1993. On the morphology of trichomes and tentacles of Droseraceae Salisb. Beitr. Biol. Pflanzen 67: 345-366.

Skotheim, J.M., and Mahadevan, L. 2005. Physical limits and design principles for plant and fungal movements. Science 308: 1308-1310.

Swaine, M.D., and Beer, T. 1977. Explosive seed dispersal in Hura crepitans L. (Euphorbiaceae). New Phytol. 78: 695-708.

Verbeek, N.A.M., and Boasson, R. 1993. Relationship between types of prey captured and growth form in Drosera in southwestern Australia. Aust. J. Ecol. 18: 203-207.

Vincent, O., Weißkopf, C., Poppinga, S., Masselter, T., Speck, T., Joyeux, M., Quilliet, C., and Marmottant, P. 2011. Ultra-fast underwater suction traps. Proc. R. Soc. B 278: 2909-2914.

Volkov, A.G., Foster, J.C., Ashby, T.A., Walker, R.K., Johnson, J.A., and Markin, V.S. 2010. Mimosa pudica: Electrical and mechanical stimulation of plant movements. Plant Cell Environ. 33: 163-173. 
Watson, A.P., Matthiessen, J.N., and Springett, B.P. 1982. Arthropod associates and macronutrient status of the red-ink sundew (Drosera erythrorhiza Lindl.). Aust. J. Ecol. 7: 13-22.

Williams, S.E., and Pickard, B.G. 1974. Connections and barriers between cells of Drosera tentacles in relation to their electrophysiology. Planta 116: 1-16.

Williams, S.E. 1976. Comparative sensory physiology of the Droseraceae - The evolution of a plant sensory system. Proc. Am. Philos. Soc. 120: 187-204.
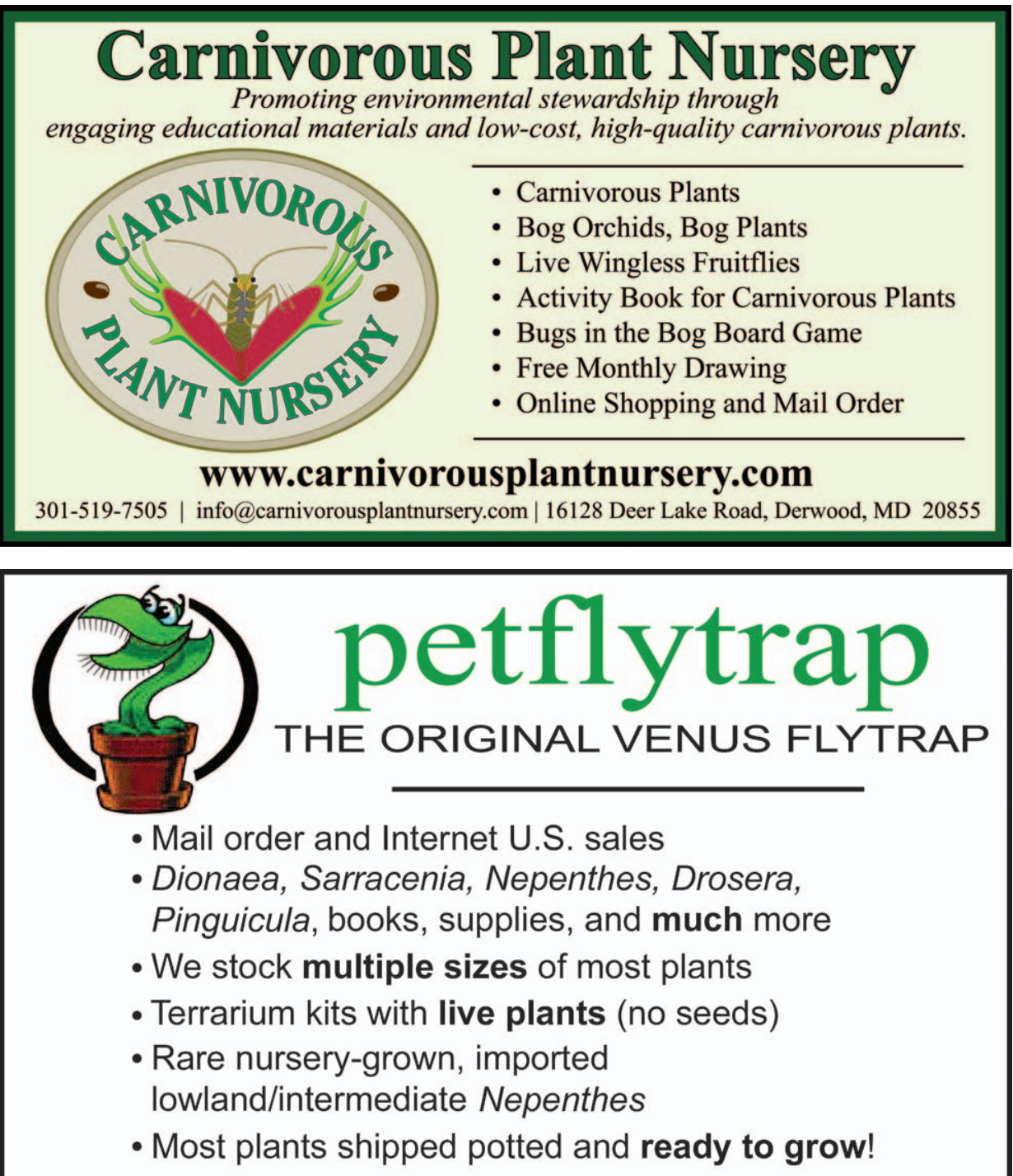

www.petflytrap.com

orders@petflytrap.com

281-433-3286 


\section{CARNIVOROUS PLANT NEWSLETTER}

Journal of the International Carnivorous Plant Society

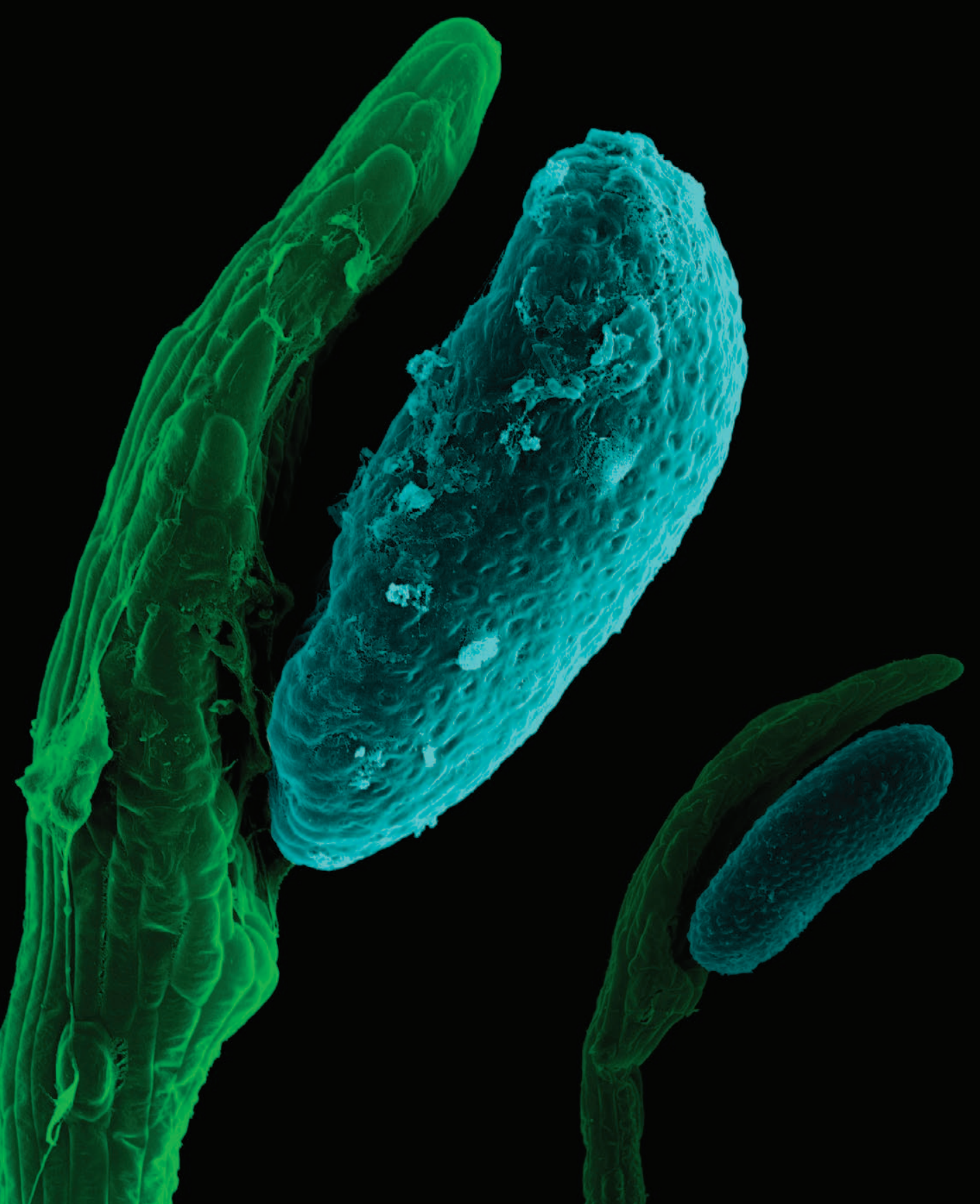




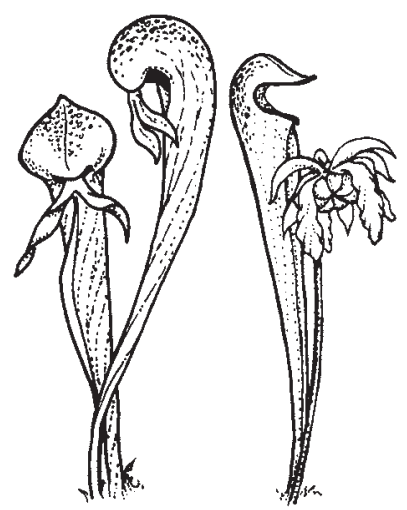

\section{CARNIVOROUS \\ PLANT \\ NEWSLETTER}

Journal of the International

Carnivorous Plant Society

www.carnivorousplants.org

Volume 42, Number 1 March 2013

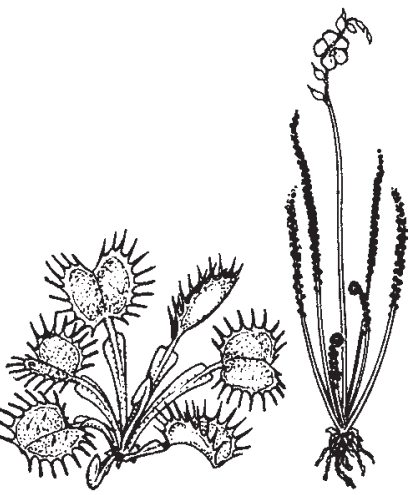

Front Cover: Colorized SEM images of terminal discs and raised heads of Drosera glanduligera snap-tentacles. Image by the Plant Biomechanics Group Freiburg and I. \& S. Hartmeyer. Article on page 4.

\section{Back Cover: The cultivar Dionaea 'Ginormous'. Photo by Damon Collingsworth. Article on page 25.}

Carnivorous Plant Newsletter is dedicated to spreading knowledge and news related to carnivorous plants. Reader contributions are essential for this mission to be successful. Do not hesitate to contact the editors with information about your plants, conservation projects, field trips, or noteworthy events. Advertisers should contact the editors. Views expressed in this publication are those of the authors, not the editorial staff.

All correspondence regarding dues, address changes and missing issues should be sent to the Membership Coordinator at the ICPS. Do not send such correspondence to the editors. Checks for subscriptions should be made to the ICPS in US funds. Dues for 2013 are $\$ 35$ for the first year of membership; renewals are $\$ 30$ per year.

ICPS, Inc.

2530 Patra Drive

Richmond, CA 94803, USA

icps@carnivorousplants.org

President

Vice President

Secretary/Treasurer

Board Member

Board Member

Board Member

Board Member

Administrator

Seed Bank Manager

CPN Editors

Managing Editor

Editor

Science Editor

Science Editor

\author{
Michael Baldwin, michael@carnivorousplants.org \\ Marcel van den Broek, marcel@carnivorousplants.org \\ Richard Myers, richard@carnivorousplants.org \\ Brian Barnes, Conservation Director, brian@carnivorousplants.org \\ Richard Nunn, richardnunn@carnivorousplants.org \\ Jan Schlauer, jan@carnivorousplants.org \\ Bob Ziemer, bob@carnivorousplants.org \\ Cindy Slezak, cindy@carnivorousplants.org \\ John Brittnacher, john@carnivorousplants.org \\ editor@carnivorousplants.org \\ Bob Ziemer \\ Barry Rice \\ Fernando Rivadavia \\ Jan Schlauer
}

Date of effective publication of the December 2012 issue of Carnivorous Plant Newsletter: 30 November 2012.

The ICPS is the International Cultivar Registration Authority (ICRA) for the names of cultivated carnivorous plants according to the International Code of Nomenclature for Cultivated Plants. Send relevant correspondence to the ICPS, Inc.

Carnivorous Plant Newsletter is published quarterly in March, June, September, and December by the ICPS, Inc., 2530 Patra Drive, Richmond, CA 94803, USA. Periodicals postage paid at Richmond, CA and additional mailing offices. Postmaster: Send address changes to ICPS, Inc., PMB 322, 1564-A Fitzgerald Drive, Pinole, CA 94564-2229, USA. Printed by Allen Press, Inc., 810 E. 10th Street, Lawrence, KS 66044. Logo and masthead art: Paul Milauskas. (C) 2013 Carnivorous Plant Newsletter. All rights reserved. ISSN \#0190-9215 